\title{
Death Diagnosis Domain
}

National Cancer Institute

\section{Source}

National Cancer Institute. Death Diagnosis Domain. NCI Thesaurus. Code C95087.

A subject domain utilized for the submission of information encompassing and representing data, vocabulary or records related to death diagnosis. 